\title{
Infraestructura e integración regional: la conformación del sistema vial Santa Fe-Paraná entre la conexión de la Mesopotamia argentina y el Corredor Bioceánico Central
}

Estefanía Szupiany

Instituto de Humanidades y Ciencias Sociales del Litoral (IHUCSO Litoral. UNL-CONICET)

Doctora en Arquitectura (Universidad Nacional de Rosario), becaria postdoctoral CONICET. Docente de la Facultad de Arquitectura, Diseño y Urbanismo, UNL, Santa Fe.

eszupiany@gmail.com

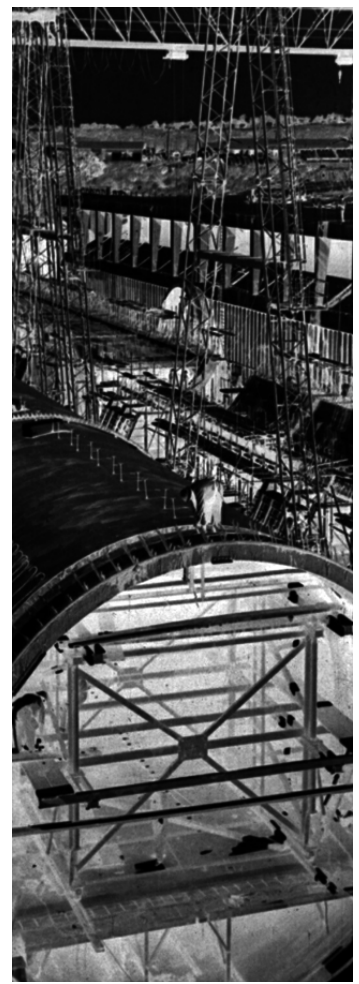

http://dx.doi.org/10.30972/crn.30304930 


\section{Infraestructura e integración regional: la conformación del sistema vial Santa Fe- Paraná entre la conexión de la Mesopotamia argentina y el Corredor Bioceánico Central}

\section{Resumen}

La noción de integración regional comenzó a ser promovida por los gobiernos latinoamericanos hacia mediados del siglo XX, en el marco del programa desarrollista gestado alrededor de la CEPAL. No obstante, esta integración, que en su origen evidenciaba un carácter mayormente político-territorial, mutó hacia una integración orientada en términos económicos a partir de los años 90 . Teniendo esto en cuenta, y en función de la importancia que el desarrollismo otorgó a las infraestructuras de conexión material, el objetivo de este artículo consiste en examinar el proceso de concreción de un conjunto de obras viales planificadas entre las décadas de 1960 y 1970. Particularmente, se analiza el caso del sistema vial Santa Fe-Paraná, el cual fue inicialmente concebido como soporte para el desarrollo y la integración de la Mesopotamia argentina con el territorio nacional y, posteriormente, para la consolidación del Corredor Bioceánico Central (Coquimbo-Porto Alegre).

\section{Palabras clave}

Integración regional, infraestructura vial, Mesopotamia argentina, corredor bioceánico.

\section{Infrastructure and regional integration: the conformation of the Santa Fe-Paraná road system between the connection of the Argentine Mesopotamia and the Central Bioceanic Corridor}

\section{Abstract}

The notion of regional integration began to be promoted by the Latin American governments towards the middle of the 20th century, in the framework of the developmental program created around ECLAC. However, this integration, which at its origin evidenced a mostly political-territorial character, mutated towards an integration oriented in economic terms since the 1990s.

Bearing this in mind, and depending on the importance that developmentalism gave to material connection infrastructures, the objective of this article is to examine the process of concretion of a set of road infrastructures planned between the 1960s and 1970s. In particular, the case of the Santa Fe-Paraná road system is analyzed, which was initially conceived as a support for the development and integration of the Argentine Mesopotamia with the national territory and, later, for the consolidation of the Central Bioceanic Corridor (Coquimbo-Porto Alegre).

\section{Keywords}

Regional integration, road infrastructure, Argentine Mesopotamia, bioceanic corridor.

\section{Infraestrutura e integração regional: a conformação do sistema viário Santa Fé-Paraná entre a conexão da Mesopotâmia Argentina e o Corredor Bioceânico Central}

\section{Resumo}

A noção de integração regional começou a ser promovida pelos governos latino-americanos em meados do século XX, no marco do programa de desenvolvimentismo criado em torno da CEPAL. No entanto, essa integração, que originalmente evidenciava uma natureza principalmente político-territorial, mudou para uma integração orientada em termos econômicos a partir dos anos 90. Levando isso em conta e dependendo da importância que o desenvolvimentismo conferiu a infraestrutura de conexão material, o objetivo deste artigo é examinar o processo de concretização de um conjunto de obras rodoviárias planejadas entre as décadas de 1960 e 1970. Em particular, é analisado o caso do sistema viário Santa Fé-Paraná, que foi inicialmente concebido como um suporte para o desenvolvimento e integração da Mesopotâmia argentina com o território nacional e, posteriormente, à consolidação do Corredor Bioceânico Central (Coquimbo-Porto Alegre).

\section{Palavras-chave}

Integração regional, infraestrutura viária, Mesopotâmia argentina, corredor bioceânico. 


\section{Introducción}

A mediados del siglo XX, el desarrollismo se constituyó en base del enfoque económico estructuralista gestado alrededor de la Comisión Económica para América Latina (CEPAL). Los teóricos de esta comisión, sobre todo Raúl Prebisch, afirmaron que, en el largo plazo, se producía un deterioro en los términos de intercambio entre los países centrales y los periféricos, lo que redundaba en un beneficio para los estados industrializados y en un perjuicio para los productores de materias primas, lo cual impedía una distribución equitativa de los frutos del progreso técnico. En este marco, la noción de integración regional comenzó a ser promovida por los gobiernos de América Latina, haciendo foco en fenómenos estructurales de la realidad internacional, como las asimetrías, la competencia entre desiguales y la profundización de las brechas, fenómenos desestimados por el pensamiento liberal (LAREDo, 1994). En Argentina, la aplicación del pensamiento económico estructural comenzó a concretarse durante la presidencia de Arturo Frondizi (1958-1962), quien intentó restablecer el poder estatal con el fin de diseñar políticas económicas y sociales que fortalecieran la estrategia de desarrollo nacional. No obstante, esta integración de carácter estructuralista —enfocada en una integración político-territorial durante las décadas de 1960 y 1970— parece haber mutado hacia una integración orientada en términos económicos -básicamente, facilitando las áreas de libre comercio y la unión aduanera-, en el marco de las políticas neoliberales implementadas tras el Consenso de Washington en 1989.

En ese marco, y en función de la importancia que el desarrollismo otorgó a las infraestructuras de conexión material, el objetivo de este artículo consiste en examinar el proceso de concreción de un conjunto de obras viales planificadas entre las décadas de 1960 y 1970, ejecutadas total o parcialmente a lo largo del último medio siglo. En particular, se propone el análisis del caso del sistema vial extendido entre las ciudades argentinas de Santa Fe (SF) y Paraná (P) o, en términos regionales, entre el Litoral y la Mesopotamia. Este caso incluye una serie de infraestructuras concebidas como soporte necesario para el desarrollo, y dirigida a la integración de la Mesopotamia al territorio nacional. Ahora bien, atravesado el período desarrollista y con algunas obras todavía pendientes, el sistema vial SF-P se convirtió, en la década de 1990, en el soporte material de un tramo clave para la consolidación del Corredor Bioceánico Central Coquimbo-Porto Alegre (en adelante, $\mathrm{CBC}$ ). Esta conexión bioceánica fue promovida como estrategia para el desarrollo geopolítico de los países sudamericanos respecto de la cuenca del Pacífico, en el marco de la progresiva consolidación 
1. Cabe destacar que el presente artículo forma parte de un proyecto de investigación aún en curso, en el cual se plantea profundizar en el análisis de las obras pendientes del sistema vial SF-P. Esta indagación, que va a desarrollarse en etapas ulteriores, supone la utilización de otras técnicas metodológicas, además del análisis documental, tales como entrevistas en profundidad a actores clave. del MERCOSUR, signada por la noción de una integración regional económica o, como lo denomina SANAHUja (2008), un "regionalismo abierto" de tendencia neoliberal.

Para dar cuenta de esta mutación, luego de relatar brevemente la relación entre el programa desarrollista y el impulso que recibió la infraestructura vial en Argentina durante las décadas de 1960 y 1970, se ofrece una reconstrucción del proceso de concreción del sistema vial SF-P, organizado de manera cronológica en función del período de construcción de cada obra. La estrategia metodológica empleada consiste en un análisis cualitativo de los discursos emergentes durante el proceso de ideación y ejecución de las infraestructuras, extraídos de fuentes documentales, tales como crónicas periodísticas de la prensa local y artículos de opinión y divulgación en revistas temáticas de interés regional. La búsqueda y selección de estas fuentes consistió, principalmente, en una investigación documental desarrollada en la Hemeroteca del Archivo General de la Provincia de Santa $\mathrm{Fe}^{1}$.

\section{Desarrollismo e infraestructura vial}

En el momento en que Frondizi asume la presidencia de la Nación, la ilusión generalizada radicaba en la promesa de sacar al país de su estancamiento y de su atraso a partir de un audaz programa de modernización y desarrollo, en sintonía con la política de industrialización por sustitución de importaciones que había sido adoptada en años anteriores. Las condiciones favorables que ofrecían estas políticas desarrollistas atrajeron inversiones extranjeras, cuyos capitales incrementaron la capacidad productiva e industrial y fomentaron la instalación de plantas modernas en las principales ciudades del país. En este contexto, comenzó a prestarse una especial atención a la construcción de grandes obras de infraestructura, pues eran concebidas como el soporte necesario para la modernización que Argentina necesitaba, precisamente vinculada con la integración de los centros de producción dispersos en el territorio nacional. A partir de esa premisa, las décadas de 1960 y 1970 fueron testigos de grandes emprendimientos, sobre todo en el ámbito de la infraestructura vial y de transporte. En ese marco, se llevaron a cabo diversas obras: el túnel subfluvial Raúl Uranga-Carlos Sylvestre Begnis (1961-1969), que une las ciudades de Santa Fe y Paraná; la autopista Rosario-Santa Fe (1966-1972); el puente General Manuel Belgrano (1967-1973), que une las ciudades de Resistencia y Corrientes, y el complejo Zárate Brazo Largo (19701977) (MÜLLER ET AL., 2018). 
En el ámbito propio de la vialidad, cabe señalar algunos hitos importantes. Ante el deterioro sufrido por el sistema caminero entre 1948-1958, y con el fin de remediar esa situación, en 1958 se firmó del Decreto Ley 505/1958, por medio del cual la Dirección Nacional de Vialidad (DNV) recobraba su autonomía ${ }^{2}$, se establecía un nuevo sistema de coparticipación federal y se disponían nuevos impuestos con el fin de dotar de recursos al Fondo Nacional de Vialidad, también creado por dicha norma. Con el objetivo de complementar ese fondo, se sancionó la Ley N.` 15.274/1960, que establecía un gravamen para los vehículos mayores a doce toneladas y para los neumáticos. Esas leyes, a su vez, se complementaron con un ambicioso plan de obras, que habría de ser llevado a cabo durante la siguiente década.

Si se mira hacia Santa Fe, Macor y Piazzesi (2011, p. 434) advierten que "el espacio provincial santafesino confirma, con pocos matices, el derrotero político nacional de estos años”. En efecto, las gobernaciones de Carlos Sylvestre Begnis (1958-1962) y Aldo Tessio (1963-1966) se mostraron muy alineadas con las presidencias de Frondizi e Illia, respectivamente. Sylvestre Begnis, quien analizaba los problemas de Santa Fe en una clave similar a la de Frondizi, consideraba que el estancamiento nacional y provincial solo podía superarse a partir de una sustantiva mejora de la capacidad energética y de la construcción de vías de comunicación. A partir de esa convicción, en noviembre de 1958 se sancionó la Ley Provincial N. ${ }^{\circ}$ 4908, por la cual no solo se estableció la adhesión de Santa Fe al Fondo Nacional instituido por el Decreto-Ley 505/58, sino que también se creó la Dirección Provincial de Vialidad (DPV) como un ente autárquico:

El período [1958-1966] se inició con gran fuerza, proyectándose $4000 \mathrm{~km}$ de rutas pavimentadas, así como con el objetivo de realizar diversas obras y puentes considerados estratégicos [...] El Gobierno entendía que la obra vial era un factor preponderante en el propósito de reactivar económicamente a la provincia (DPV, 1988, p. 58).

Con ese objetivo, se puso en marcha un plan que se proponía construir y ampliar diversas rutas y mejorar los accesos a las ciudades de Santa Fe y Rosario, principales centros urbanos de la provincia. Este proyecto formaba parte de un plan más amplio, a cargo del Departamento de Accesos a las Grandes Ciudades de la DNV. Un resumen de ese proyecto puede encontrarse en la disertación realizada por el jefe del mencionado departamento (LuXARDo, 1961), que incluye los proyectos que habrían de llevarse a cabo en Buenos Aires, Bahía Blanca, Mendoza, Córdoba, Rosario y Santa Fe. Asimismo, durante este período se encaró una de las obras más importantes y emblemáticas que se han realizado en la región litoral:
2. La DNV había sido creada en 1932 a partir de la sanción de la Ley Nacional de Vialidad . $^{\circ}$ 11.658. Luego del período considerado la "era dorada de la vialidad" en Argentina, la DNV fue intervenida en 1943 tras el golpe de Estado liderado por el Grupo de Oficiales Unidos. 
3. Entre las justificaciones del aislamiento de la Mesopotamia con respecto al resto del territorio nacional,

cabe mencionar aquella sostenida por las fuerzas militares. Tras la Guerra del Paraguay, existió una hipótesis de conflicto armado entre Argentina y Brasil, en el que el territorio conformado por las provincias de Entre Ríos, Corrientes y Misiones podría resultar invadido.

El río Paraná, por lo tanto, representaba un recurso estratégico para la defensa del gobierno central, y se desestimaba, desde Buenos

Aires, la construcción de infraestructuras de conexión. el ya mencionado túnel subfluvial entre Santa Fe y Paraná, como así también la autopista Santa Fe-Rosario-Arroyo del Medio, la cual formaba parte de un proyecto que involucraba a las provincias de Buenos Aires y Córdoba, dirigido a unir las capitales provinciales a través de un sistema moderno de vías rápidas.

\section{De la integración del territorio nacional a la inserción en el CBC: el caso del sistema vial Santa Fe-Paraná}

La región mesopotámica argentina -integrada por las provincias de Entre Ríos Corrientes y Misiones- es un territorio delimitado por diversos afluentes, entre ellos los ríos Paraná, Uruguay e Iguazú. Esta característica insular mantuvo aislada a la Mesopotamia del resto del continente hasta la concreción de las primeras infraestructuras de conexión física a mediados del siglo $\mathrm{XX}^{3}$. Previamente, el enlace era resuelto mediante servicios de balsas; no obstante, el paulatino incremento del parque automotor y los nuevos intercambios evidenciaron la obsolescencia de dicho sistema. En consecuencia, el problema alcanzó carácter público en la década de 1950, cuando comenzó a adquirir mayor importancia en la agenda gubernamental en el marco de las políticas dirigidas al desarrollo económico nacional ( $\mathrm{C}_{\mathrm{A}}$ MARDA \& MATEO, 2018).

Tras la construcción del puente Paso de los Libres (Argentina)-Uruguaiana (Brasil), primera conexión material de la Mesopotamia sobre el río Uruguay, el cruce sobre el río Paraná se convirtió en una necesidad imperiosa. En ese marco, se construyó el túnel subfluvial Uranga-Sylvestre Begnis, cuyos vaivenes y especificidades se comentan más abajo. Ahora bien, más allá de la magnitud que adquirió esta obra, lo que se intenta destacar aquí es su inclusión en un sistema integral de infraestructuras que hicieron posible la efectiva conexión de la Mesopotamia a través del río Paraná, en particular, a través del sistema vial SF-P.

Algunas décadas más tarde, precisamente en los años 90, comenzó a difundirse la noción de corredor bioceánico. Entre los trazados definidos por la Iniciativa de Integración Económica IIRSA, el CBC consiste en una franja de territorio que atraviesa las regiones Central de Chile, Cuyo y Centro de Argentina y la conformada por el territorio del Uruguay junto al Estado brasileño de Rio Grande do Sul (HeRmidA, 2017). Su infraestructura está conformada por un complejo multimodal de cargas; no obstante, en el territorio argentino comenzó a jerarquizarse un eje en particular: el CBC Coquimbo-Porto Alegre, de infraestructura básicamente 
vial (figura 1). En este marco, el sistema vial SF-P se convirtió en un nudo de comunicaciones central para las funciones del corredor, cuya iniciativa impulsó su readecuación a partir de la remodelación y ejecución de nuevas infraestructuras.

A continuación, se ofrece una reconstrucción del proceso de concreción de las obras viales que integran dicho sistema, ideadas en el marco del impulso desarrollista entre 1960 y 1970, pero cuya concreción no se completó sino hasta el nuevo siglo. Momento en que, como se verá en las próximas líneas, emerge la figura del $\mathrm{CBC}$ en las justificaciones discursivas que impulsan la materialización de las obras pendientes. Para una mejor comprensión, se propone una exposición cronológica de las infraestructuras (en función de su momento de construcción), cuyas referencias se ofrecen en la figura 2.

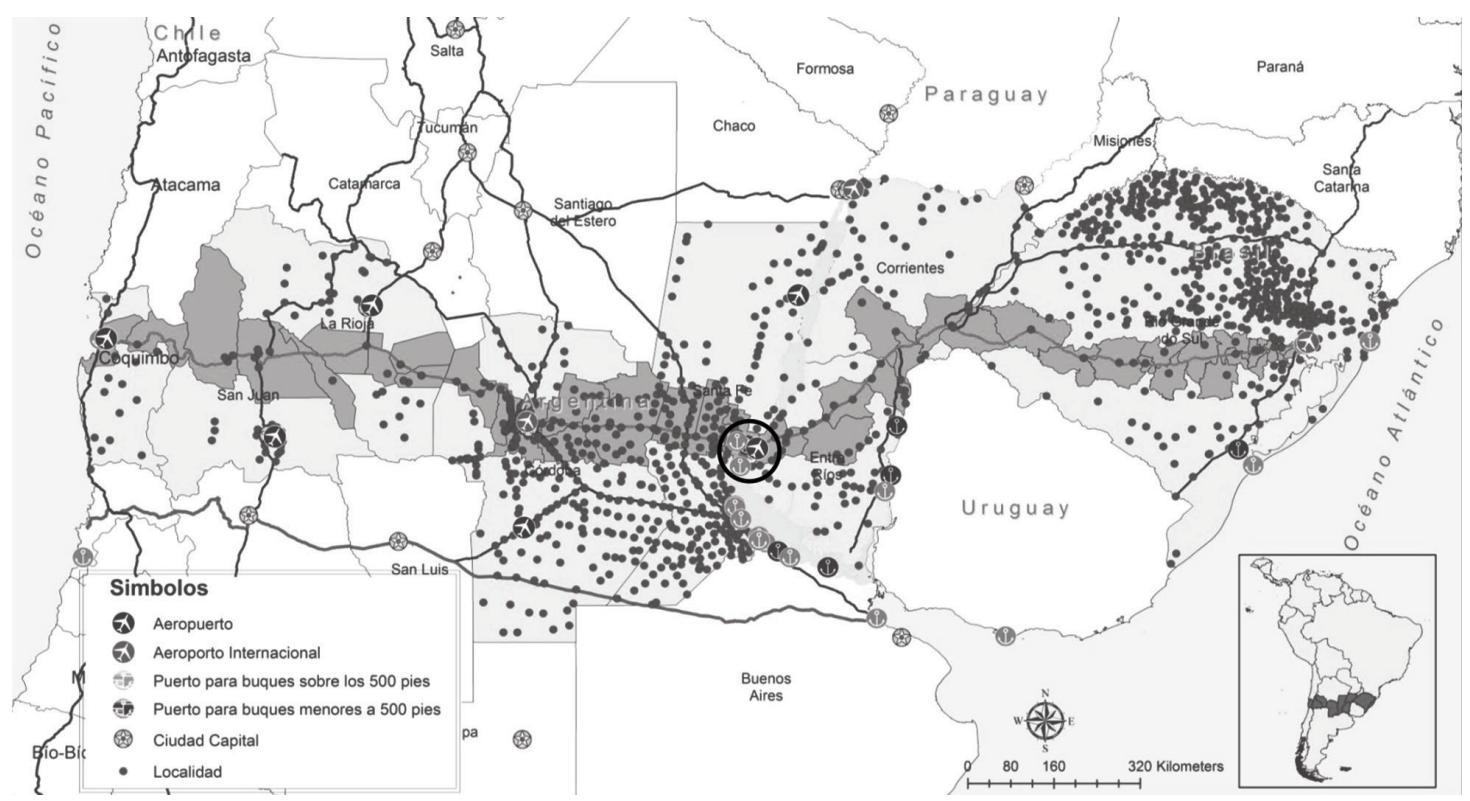

Figura 1. Ubicación del sistema vial SF-P en el marco del trazado del CBC. Fuente: intervención propia sobre imagen extraída de MORALES LETZKUS, 2014 


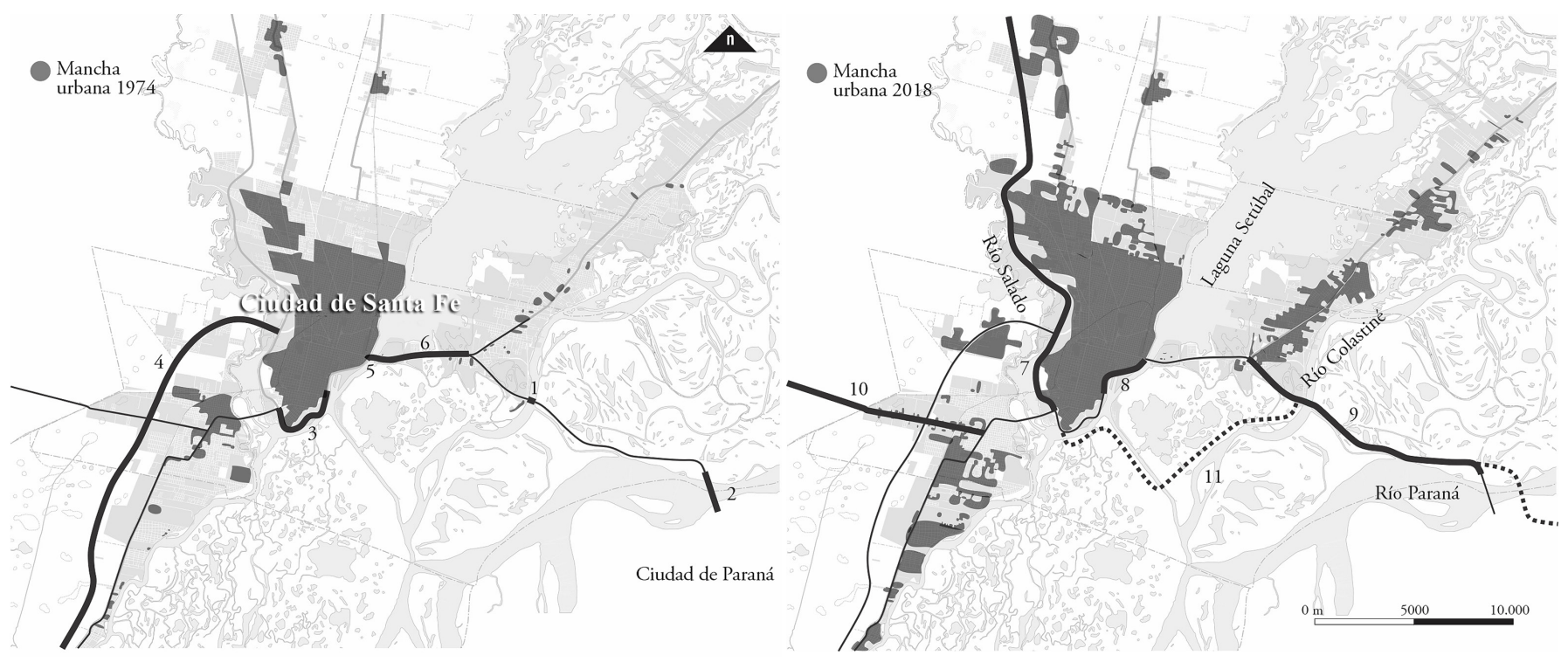

Figura 2. Infraestructuras que integran el sistema vial SF-P. (1) Puente sobre el río Colastiné (1959-1967); (2) túnel subfluvial Raúl Uranga-Carlos Sylvestre Begnis (1961-196 9); (3) avenida de Circunvalación Sur (1963-1969); (4) autopista Rosario-Santa Fe (1966-1972); (5) puente y viaducto Nicasio Oroño (19681971); (6) autovía Ruta Nacional 168 (1971-1973/1978-1979); (7) avenida Circunvalación Oeste (1994-1997); (8) avenida Circunvalación Este (2004-2005); (9) autovía Ruta Nacional 168 (2007-2011); (10) autovía Ruta Nacional 19 (2008-2011); (11) puente Santa Fe-Paraná, pendiente. Fuente: elaboración propia

\section{Puente sobre el río Colastiné (1959-1967)}

Al tiempo que la conexión con la Mesopotamia se convertía en una problemática central para la integración del territorio nacional, el sistema de balsas para el cruce de los ríos Colastiné y Paraná resultaba un medio cada vez más anticuado e inviable en términos económicos. Lo que en un principio representaba un placentero paseo fluvial para los automovilistas, en la década del 60 se había convertido en un viaje lento y fastidioso. Ante esa situación, la conexión de la ciudad de Santa Fe con la Mesopotamia experimentó un período 
de gran transformación a partir de las obras dirigidas a reconfigurar el trazado de la Ruta Nacional 168 (RN 168), convirtiéndola en autovía. Entre las nuevas infraestructuras proyectadas, el puente sobre el río Colastiné y el túnel subfluvial, bajo el lecho del Paraná, materializaron un viejo anhelo planteado a principios del siglo XX ${ }^{4}$. En 1959, un periódico local anunciaba la construcción de un puente de 500 metros de extensión sobre el río Colastiné, proyectado y licitado por la DNV:

La tan comentada necesidad de vincular con eficacia y rapidez las orillas del Paraná, esto es el centro de la República y la vasta Mesopotamia argentina con las lógicas consecuencias favorables para la conexión con zonas de los hermanos países de Uruguay y Brasil, está en víspera de ser satisfecha en parte considerable (Diario El Litoral, 18/03/1959, p. 4).

Para finales del mismo año, la obra se encontraba en pleno desarrollo, aunque su continuidad a través del río Paraná aún no estaba definida (DiARIo El LitoraL, 29/12/1959). Finalmente, luego de más de siete años de trabajo, en 1967 se anunció la culminación de las obras (Diario El Litoral, 21/01/1967).

\section{Túnel subfluvial Raúl Uranga-Carlos Sylvestre Begnis ${ }^{5}$ (1961-1969)}

Dos años más tarde, en diciembre de 1969, también quedó inaugurado y habilitado al tránsito el túnel subfluvial Raúl Uranga-Carlos Sylvestre Begnis, tramo central del sistema vial SF-P. Con el título "Hemos ganado la gran batalla en la larga guerra contra el atraso y el aislamiento", la prensa local resaltaba el discurso del por entonces gobernador de Entre Ríos, Ricardo Favre:

Todas las grandes obras que se vienen realizando no serán sino otros nuevos caminos a través de los cuales se desplacen las mercaderías y los hombres hacia la gran urbe. Cambiar las estructuras significa transformar la proporción en que se distribuye nuestra población entre el gran Buenos Aires y el interior, significa energía industrial barata, transportes económicos, puertos eficientes, servicios financieros promocionales y cargas tributarias diferenciales para lograr estructurar economías regionales y locales bien complementadas y organizadas para la gran integración de nuestro país (Diario El LitoRaL, 13/12/1969, p. 4).

Asimismo, el gobernador de la provincia de Corrientes destacaba la obra del túnel como una "rebelión del interior frente al centralismo porteño", y agregaba que "ha llegado el momento de defender nuestra propia producción” (Diario El Litoral, 14/12/1969, p. 1).
4. La posibilidad de construir un túnel o puente entre las ciudades de Santa Fe y Paraná fue planteada en 1911, mediante un proyecto presentado al Congreso Nacional.

5. Hasta el año 2001, momento en que se decidió renombrar al túnel en homenaje a los gobernadores que hicieron posible la concreción de la obra, era conocido como túnel subfluvial Hernandarias. 
6. La decisión de construir un túnel subfluvial en lugar de un puente fue el resultado de un conflicto políticojurisdiccional. Luego de la presentación de sucesivos proyectos de puentes invalidados por el Ejecutivo

Nacional, las provincias optaron por utilizar el lecho del río Paraná perteneciente a su jurisdicción, con el objetivo

de lograr cierta autonomía respecto del dominio de jurisdicción nacional sobre el espacio aéreo.
La iniciativa para la construcción de una vinculación carretera entre ambas capitales se remonta muy lejos en el tiempo, pero su proyecto más importante se inició -luego de algunas tentativas en la década anterior ${ }^{6}$ - en 1952 y fue declarado una obra de interés nacional en 1956, mediante el Decreto N. ${ }^{\circ} 7122$ del Poder Ejecutivo Nacional. Ese mismo año se efectuó una licitación por intermedio del Ministerio de Obras Públicas (MOP), aunque dicho proceso quedó sin efecto debido al rechazo de todas las ofertas presentadas. Ante las demoras, en 1960, los gobernadores de Entre Ríos y Santa Fe, Uranga y Sylvestre Begnis, suscribieron un tratado interprovincial para la construcción de un túnel subfluvial de acuerdo con el anteproyecto presentado por los ingenieros Carlos Laucher y Ernesto Altgelt; una iniciativa ampliamente celebrada en el ámbito local, sobre todo ante la centralidad que solía asumir Buenos Aires en los procesos de toma de decisión.

Admiración hacia quienes la historia tendrá que reconocerles el tremendo coraje de haber desafiado la indiferencia ultrajante de la Nación en su vertical gesto federalista, que es algo así como poner de pie a las provincias (Revista Tiempo, diciembre de 1967, p. 32).

Debe recordarse que cuando los gobiernos de Santa Fe y Entre Ríos resolvieron encarar la unión de la Mesopotamia al continente no hallaron ni siquiera opinión, encontraron vacío absoluto en todos los órdenes. Paraná y Santa Fe están muy lejos de la Avenida General Paz y los hombres que opinan desde los grandes estrados muy pocas veces tienen la vista suficiente para ver lo que conviene al país, que vive y trabaja más allá de esa frontera artificial que ellos levantan cada vez más, sin pensar que es solamente el límite de un municipio (Revista La Nota Santafesina, diciembre de 1964, p. 6).

En 1961 se firmó el contrato para el proyecto y la ejecución de la obra con un consorcio integrado por tres empresas de Alemania, Italia y Argentina, adoptándose el sistema de peaje por treinta años. Los trabajos de dragado se iniciaron en el año siguiente; no obstante, a mediados de 1963, la obra quedó paralizada por inconvenientes de financiación y fue retomada veinte meses más tarde, luego de un préstamo del gobierno nacional. A partir de entonces, los trabajos continuaron a buen ritmo hasta su inauguración, en diciembre de 1969 (figura 3).

\section{Avenida de Circunvalación Sur (1963-1969)}

Al tiempo que el traslado mediante balsas era reemplazado por estos nuevos enlaces sobre los ríos Colastiné y Paraná, el sistema vial SF-P se complementaba con infraestructuras en 
Infraestructura e integración regional: la conformación del sistema vial Santa Fe-Paraná entre la conexión de la Mesopotamia argentina y el Corredor Bioceánico Central
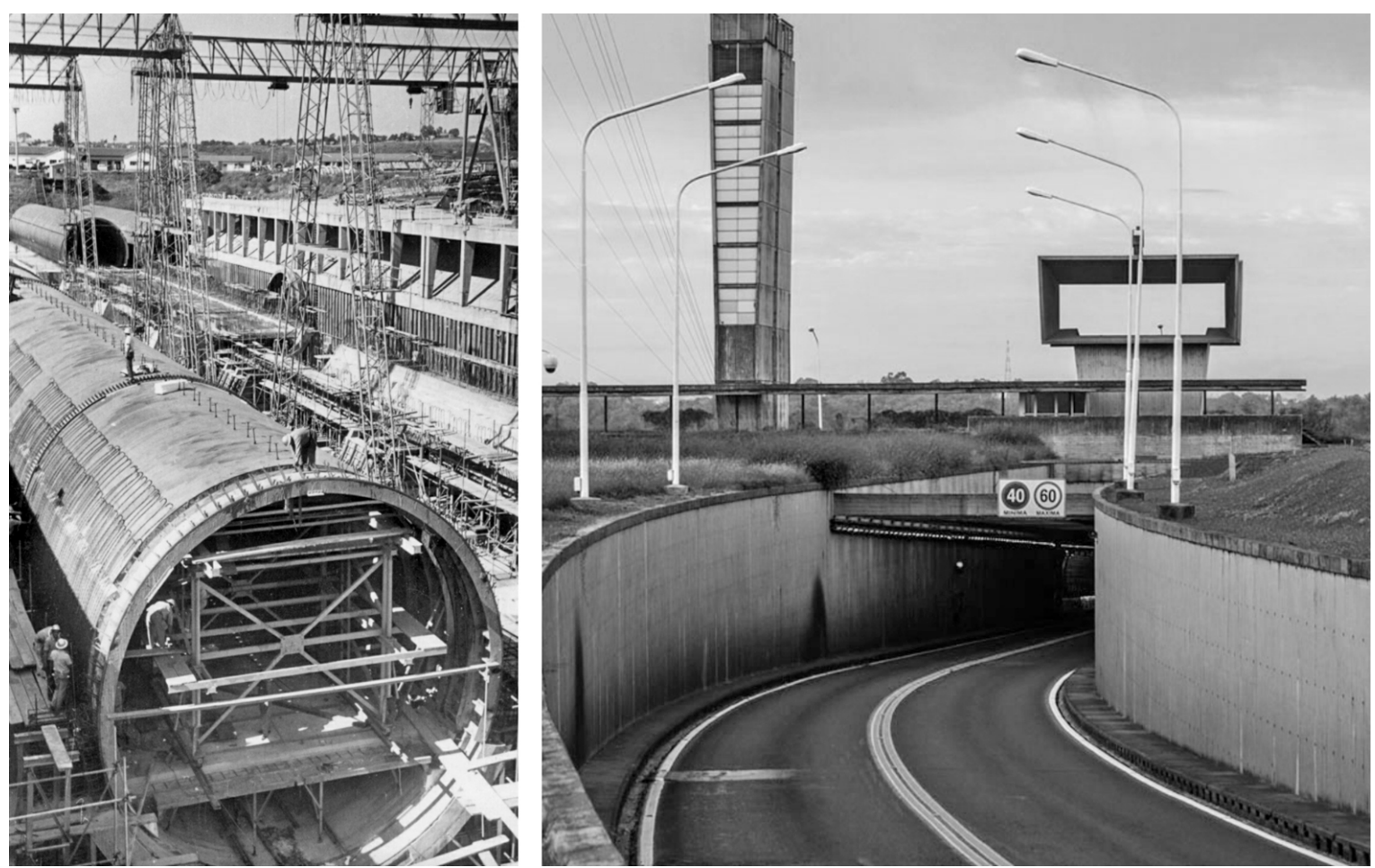

Figura 3. Túnel Subfluvial Raúl Uranga-Carlos Sylvestre Begnis. Izquierda, construcción de los tubos en dique seco; derecha, vista de la rampa de acceso al túnel. Fuente: ENTE INTERPROVINCIAL TÚNEL SUBFLUVIAL (s/f)

torno del tejido urbano de la ciudad de Santa Fe. Durante la década de 1950, se firmó un convenio entre la DNV y la DPV con el objetivo de llevar a la práctica la idea de una avenida de circunvalación para dicha ciudad. El proyecto completo contemplaba distintas secciones, planteando un anillo de cierre a la planta urbana. Las primeras definiciones apuntaron a la consolidación del tramo sur de la avenida, que iba a ser extendida entre el acceso a la ciudad por la Ruta Nacional 11 (RN11), desde el puente Carretero sobre el río Salado, hasta 
empalmar con la avenida 27 de Febrero (figura 4). La habilitación de este primer tramo de la avenida Circunvalación se concretó a fines de 1969, al tiempo que se evidenciaba la urgencia de su prolongación para alcanzar la integralidad del sistema vial:

$\mathrm{Al}$ respecto no hay nada resuelto, pero resulta oportuno alertar sobre esta situación, ya que la próxima habilitación del túnel subfluvial, la posterior de la autopista y el nuevo puente, convertirán a Santa Fe en un verdadero "nudo de tránsito”, razón por la cual debe disponerse de las vías internas que faciliten la ágil interconexión. Y en este sentido, la terminación de la avenida circunvalación resulta de imperiosa necesidad (Diario El LitoraL, 5/07/1969).

Figura 4. Avenida de Circunvalación Sur. Fuente: intervención propia sobre relevamiento fotogramétrico del Instituto Geográfico Nacional, 1980

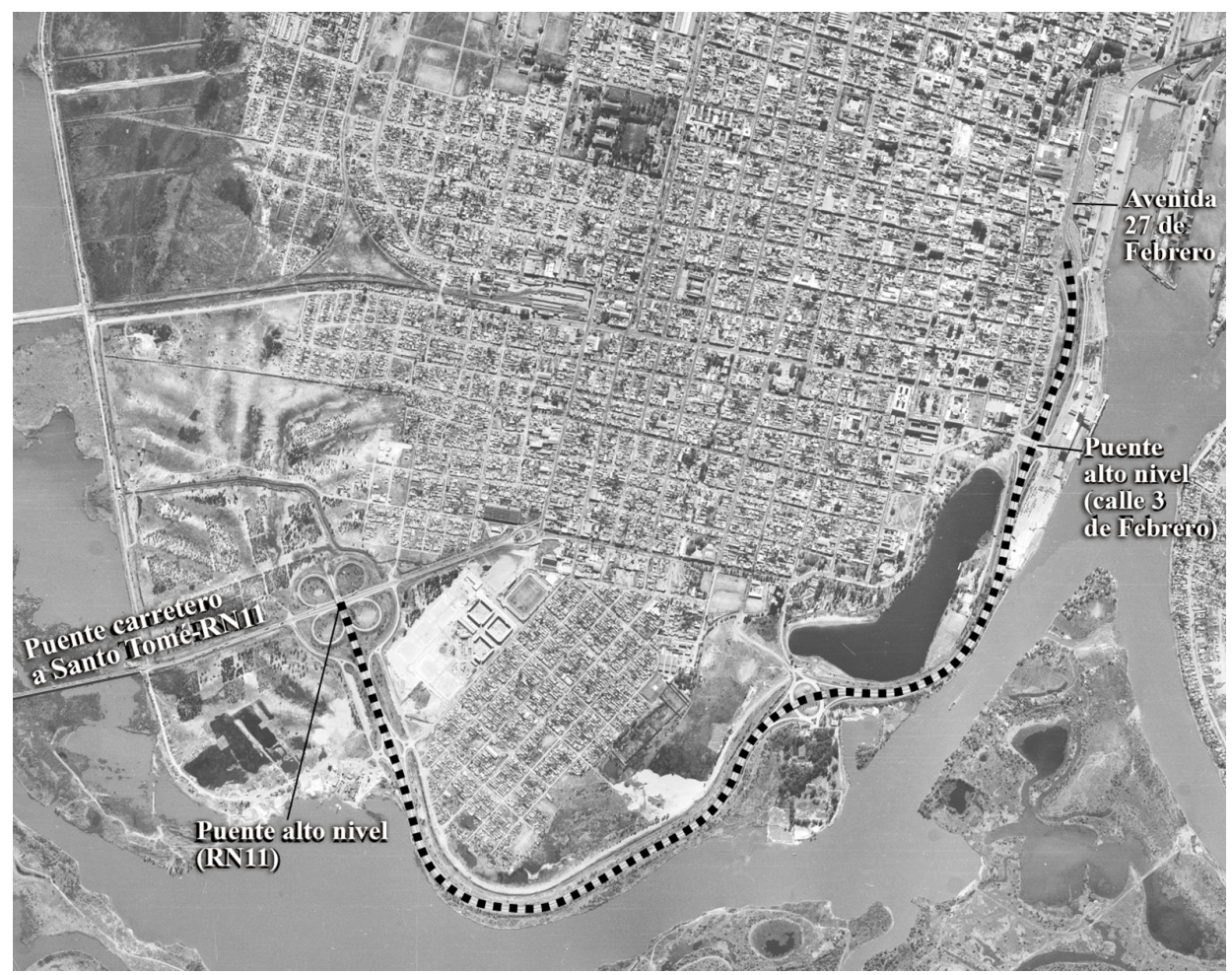


La continuidad de la avenida Circunvalación hasta el nuevo puente sobre la laguna Setúbal consistía en la remodelación de las avenidas 27 de Febrero y Leandro Alem. No obstante, en razón de la situación política y económica que atravesó el país durante la década de 1970, la intervención se redujo tan solo a obras de pavimentación y mejorado de las calzadas.

\section{Autopista Rosario-Santa Fe (1966-1972)}

En la década de 1960, comenzaron a evidenciarse los deterioros ocasionados por el aumento del tránsito vehicular en el tramo de la RN 11 extendido entre las ciudades de Santa Fe y Rosario, fundamentalmente vinculado con el transporte de cargas pesadas. A pesar de los trabajos de repavimentación y ampliación del ancho de las calzadas, su reemplazo por una autopista paralela se presentaba como una necesidad casi imperiosa, en sintonía con la opinión de los técnicos viales, quienes intercedieron a favor de su construcción. De acuerdo con los fundamentos del proyecto presentados por la DPV (1965), la nueva autopista consistía en una vía de comunicación paralela a la RN 11 destinada a mejorar la vinculación entre las dos ciudades principales de la provincia de Santa Fe (figura 5). Al mismo tiempo, la autopista permitiría enlazar, hacia el sur, con la Ruta Nacional 9 en la provincia de Buenos Aires, sirviendo de conexión con la Capital Federal y el sureste del país, y, hacia el norte, con la región mesopotámica junto a la proyectada habilitación del túnel subfluvial.

Los trabajos se iniciaron en agosto de 1966, y quedó habilitada — de manera extraoficial—a fines de 1971 en el tramo RN 19-Rosario (Diario El Litoral, 18/11/1971). No obstante, la autopista fue objeto de disputas concernientes a su definitivo destino y habilitación. Si bien la provincia dio los pasos necesarios y se determinaron los reintegros de fondos mediante un convenio celebrado entre la DPV y la DNV, dicho convenio no había sido ratificado al momento de su puesta en funcionamiento, con lo que la cesión de la autopista a Vialidad Nacional permanecía "en el aire". Esta demora, tal como se expresaba en la prensa local, era motivo de "la clásica inercia burocrática que en el orden metropolitano retarda problemas o intereses que corresponden a las provincias, como en el caso del presupuesto santafesino, aún pendientes de firmas en el ámbito del Ejecutivo central” (Diario El Litoral, 25/06/1972). Ante la inminente firma del decreto presidencial por el cual se aprobó el mencionado convenio, la inauguración oficial de la autopista Brigadier General Estanislao López se concretó en octubre de 1972 (Diario El Litoral, 4/10/1972), la primera autopista de estas dimensiones en el país. Finalmente, las incertidumbres aún irresueltas respecto de la jurisdicción de la 
autopista se resolvieron con el traspaso definitivo a la provincia y con el pago de una deuda por parte de la DNV a la DPV (Diario El Litoral, 20/09/1979).

\section{Puente y viaducto Nicasio Oroño (1968-1971)}

A mediados del siglo XX, la intensificación del tránsito desde la ciudad de Santa Fe hacia la RN 168 comenzó a experimentar serias dificultades en el cruce de la laguna Setúbal a través del puente colgante. En efecto, la estructura de este puente, inaugurado a fines de la década de 1920, no había sido diseñada para resistir las cargas y las velocidades que se registraban en la década de 1950, sobre todo con motivo del crecimiento del parque automotor y de los avances técnicos aplicados a la industria automotriz. Ante esta situación, la DNV presentó en el año 1960 el anteproyecto para la construcción de un nuevo puente carretero con accesos elevados sobre la laguna Setúbal, que sería emplazado 90 metros aguas abajo del puente colgante. A partir de esta obra, se pretendía asegurar una vía rápida de acceso a la ciudad capital teniendo en cuenta, además de las deficiencias mencionadas en el antiguo puente, la intensificación de tránsito que se daría a partir de la construcción del túnel subfluvial Santa Fe-Paraná (Diario El LitoraL, 25/05/1960; 4/10/1960).

Figura 5. Trazado de la autopista Santa FeRosario-Arroyo del Medio. Fuente: DIRECCIÓN Provincial de VIALIDAd (1965)

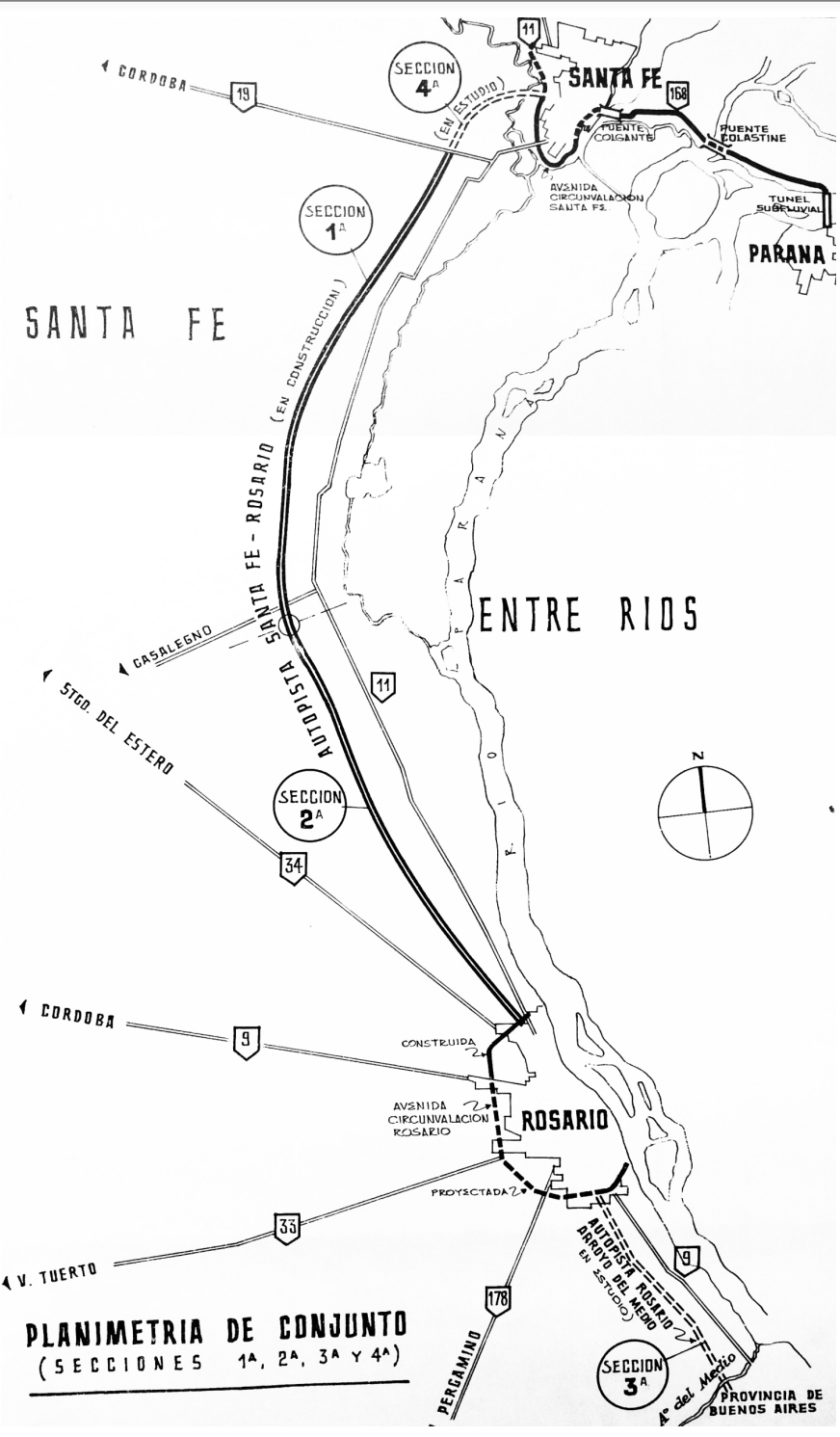


Infraestructura e integración regional: la conformación del sistema vial Santa Fe-Paraná entre la conexión de la Mesopotamia argentina y el Corredor Bioceánico Central

La licitación y adjudicación del nuevo puente se realizó en 1967, ante la urgencia de la DNV de complementar el sistema de intercomunicación vial que se impulsaría con la inauguración del túnel, y los trabajos se iniciaron en febrero de 1968. En el ámbito local se extendió la crítica acerca del desfasaje temporal en la concreción de las obras que integraban el mismo sistema vial. Mientras el gobierno provincial ultimaba detalles para la habilitación de la autopista Santa Fe-Rosario y del túnel subfluvial, el gobierno nacional iniciaba, tardíamente, las gestiones para la construcción del puente sobre la Setúbal (RevisTA Tiempo, septiembre de 1968).

Durante la etapa constructiva, el sistema técnico aplicado fue motivo de curiosidad y aclamación. Consistía en la construcción por tramos voladizos de 3,11 m cada uno desde ambas márgenes hacia su parte media, una técnica novedosa utilizada por primera vez en el país. La habilitación del puente se concretó a principios de 1971 (Diario El litoral, 14/01/1971), y ocho meses más tarde se concluyeron las obras complementarias, los sistemas de accesos

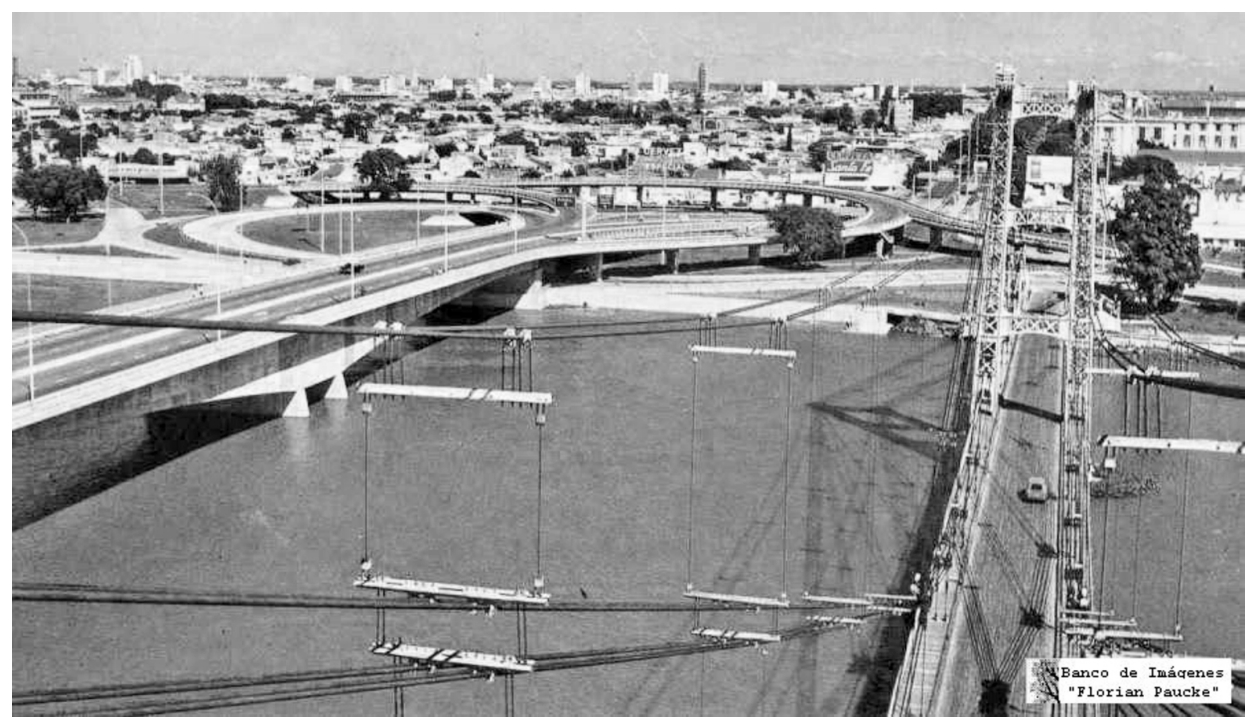

Figura 6. Vista aérea de ambos puentes sobre la laguna Setúbal, 1975; puente y viaducto Nicasio Oroño (izq.), antiguo puente colgante (der.). Fuente: banco de imágenes Florián Paucke 
y las articulaciones de ambas cabeceras (Diario El Litoral, 25/09/1971) (figura 6). La importancia que asumió su habilitación, en tanto pieza fundamental de un sistema integral de obras viales (algunas ya inauguradas, otras en construcción y algunas pendientes), deja entrever el impulso que recibió la infraestructura vial, y más precisamente los accesos a las grandes ciudades, en plena etapa del desarrollismo nacional.

Si se tiene en cuenta que esta obra forma parte de un complejo vial, en gran parte en proceso de construcción, podrá medirse cabalmente su importancia. El ensanche de la ruta 168, que tendrá dos manos hasta la Guardia, con sus puentes adecuados a la nueva medida, el nuevo ancho que se le dará a la mano única que comunica La Guardia con el puente sobre el río Colastiné y la nueva sección de la avenida circunvalación a construirse siguiendo el actual trazado de las avenidas 27 de Febrero y Leandro N. Alem, forman un todo orgánico de extraordinario valor. Es de esperar que los anuncios del ministro Gordillo fijen plazos razonables, para que Santa Fe pueda contar en el próximo quinquenio con su avenida de circunvalación completa, que incluye los tramos del oeste y del norte, integrando de esta manera un sistema con esa otra realización de magnitud que es la autopista Santa Fe-Rosario (Diario El Litoral, 25/09/1971, p. 4).

\section{Autovía Ruta Nacional 168 (1971-1973 / 1978-1979)}

Desde el 7. ${ }^{\circ}$ Distrito de Vialidad Nacional se anunció, en 1966, la reconstrucción completa de la RN 168, la cual consistía en la transformación de la ruta existente en una autovía de dos calzadas con cantero central, desde la salida del nuevo puente y viaducto Oroño hasta el acceso al túnel subfluvial (Diario El Litoral, 5/10/1966). No obstante, dos años más tarde se manifestó la necesidad de ampliar los puentes aliviadores que salvaban los pequeños cursos de agua y las cañadas existentes a lo largo de la ruta, dado que la diferencia entre el ancho de estos (6 metros) y el ancho de la nueva calzada (7,30 metros) daría como resultado un serio inconveniente a partir del incremento en el tránsito vehicular que producirá la habilitación del túnel subfluvial (DiARIO El Litoral, 12/03/1968). Concluidos estos nuevos puentes aliviadores en 1973, quedaron sin embargo desarticulados durante algunos años (Diario El Litoral, 21/01/1973), hasta el definitivo ensanche de este primer tramo de la RN 168, entre 1978-1979 (DiARIo El LitoRAL, 23/01/1979). La primera sección de la autovía se construyó desde la cabecera este del puente Oroño, y la segunda, desde el extremo inconcluso hasta el intercambiador con la Ruta Provincial 1 (RP1) (figura 7). 
Infraestructura e integración regional: la conformación del sistema vial Santa Fe-Paraná entre la conexión de la Mesopotamia argentina y el Corredor Bioceánico Central
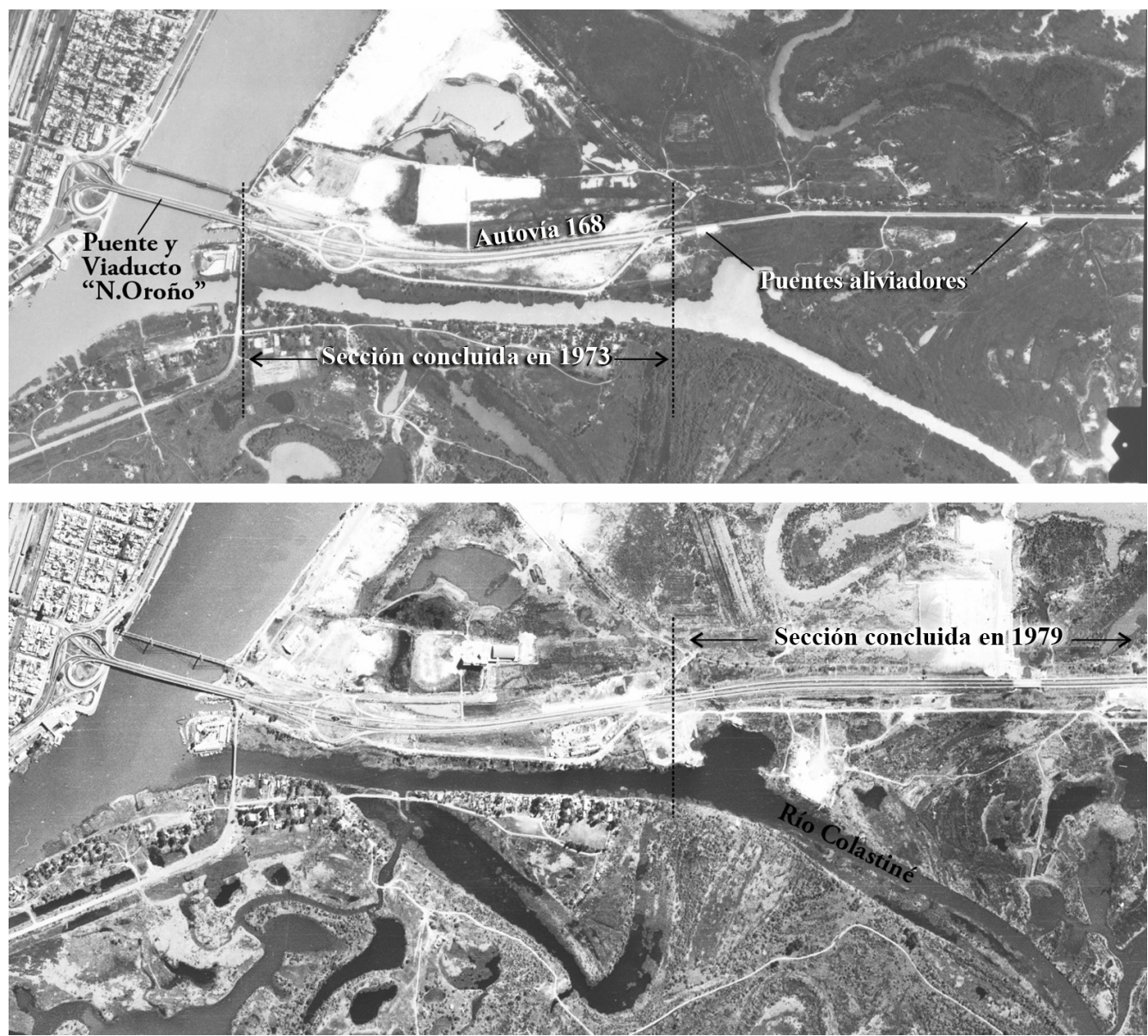

Figura 7. Fragmento de la Autovía 168 y puentes aliviadores. Arriba, construcción de la primera sección (1200 metros). Fuente: intervención propia sobre relevamiento fotogramétrico de Catastro de la provincia de Santa Fe, 1974. Abajo, construcción de la segunda sección (3500 metros). Fuente: intervención propia sobre relevamiento fotogramétrico del Instituto Geográfico Nacional, 1980 
7. De esta manera, la obra ya no respondía al proyecto original de los años 60 que proponía un cierre norte a la ciudad en sentido esteoeste, sino que se planteó como una prolongación de la circunvalación oeste en sentido norte-sur. En definitiva, a finales del siglo XX el crecimiento de la mancha urbana sobre el noroeste de la ciudad había superado ampliamente las previsiones realizadas en la década de 1960

\section{Avenida Circunvalación Oeste (1994-1997)}

Durante las últimas décadas del siglo XX, la ciudad de Santa Fe no experimentó un crecimiento demográfico muy relevante; sin embargo, sí se verificaron movimientos internos que impulsaron una mayor ocupación de los barrios emplazados en las cercanías de los bañados del río Salado. En este contexto de transformación urbana, junto a la necesaria redefinición del acceso norte a la ciudad, la concreción de la avenida de Circunvalación Oeste se convirtió en una prioridad, sobre todo para la defensa y protección de la mancha urbana comprendida entre el puente Carretero a Santo Tomé y la localidad de Recreo ${ }^{7}$. Se previó, por lo tanto, la ejecución de tres tramos claramente diferenciados, con una extensión total aproximada de 30 kilómetros: el primer tramo consistió en la readecuación del viejo Terraplén Irigoyen entre el puente Carretero y la autopista Rosario-Santa Fe (4,3 km); el segundo, desde este último hasta el sector sur del hipódromo de Las Flores, a la altura de la calle Gorostiaga $(2,3 \mathrm{~km})$. Ambos tramos fueron construidos entre 1994 y 1997, y generaron en la población aledaña cierta tranquilidad ante las crecidas del río Salado. Finalmente, tras la catástrofe hídrica del año 2003, el gobierno provincial inició los estudios previos para la construcción del tercer tramo y cierre definitivo de la avenida de Circunvalación, desde el hipódromo de Las Flores hasta el norte del núcleo urbano de la ciudad de Recreo, con una extensión aproximada de 22 kilómetros. Si bien las obras se iniciaron en 2004, su habilitación no se concretó hasta el año 2012.

\section{Avenida Circunvalación Este (2004-2005)}

El proyecto para la continuación de la avenida Circunvalación hasta el puente Oroño -a través de las avenidas 27 de febrero y Leandro Alem - fue retomado en el año 2003 por la DPV, en un marco de intensificación del tránsito regional, nacional y, fundamentalmente, internacional. La obra suponía la habilitación de una multitrocha de ocho carriles, con una longitud total de 2650 metros, comprendidos entre el principio del tramo sur de la avenida de Circunvalación y el intercambiador de acceso al puente Oroño.

No obstante, una de las principales críticas que recibió el proyecto se fundamentó en la barrera que produciría esta "gran trocha de cemento" entre el área portuaria y el tejido urbano de la ciudad. En este sentido, la Comisión Municipal de Defensa del Patrimonio Cultural sugirió recuperar el carácter urbano de esas avenidas: “Cuando decimos 'carác- 
Infraestructura e integración regional: la conformación del sistema vial Santa Fe-Paraná entre la conexión de la Mesopotamia argentina y el Corredor Bioceánico Central

ter urbano' estamos hablando de una calidad de espacio que no es precisamente el que ofrece una multitrocha o una ruta-autopista de estas características; creemos que hay sobrados elementos para reconsiderar y recapacitar sobre ciertas cuestiones" (DIARIO EL Litoral, 3/11/2003). Por otra parte, uno de los motivos centrales de la crítica fue el modo en que se gestionó el proyecto, centralizado en el gobierno provincial y sin la participación de entidades como las universidades, los colegios profesionales, las cámaras industriales y comerciales, entre otras entidades intermedias.
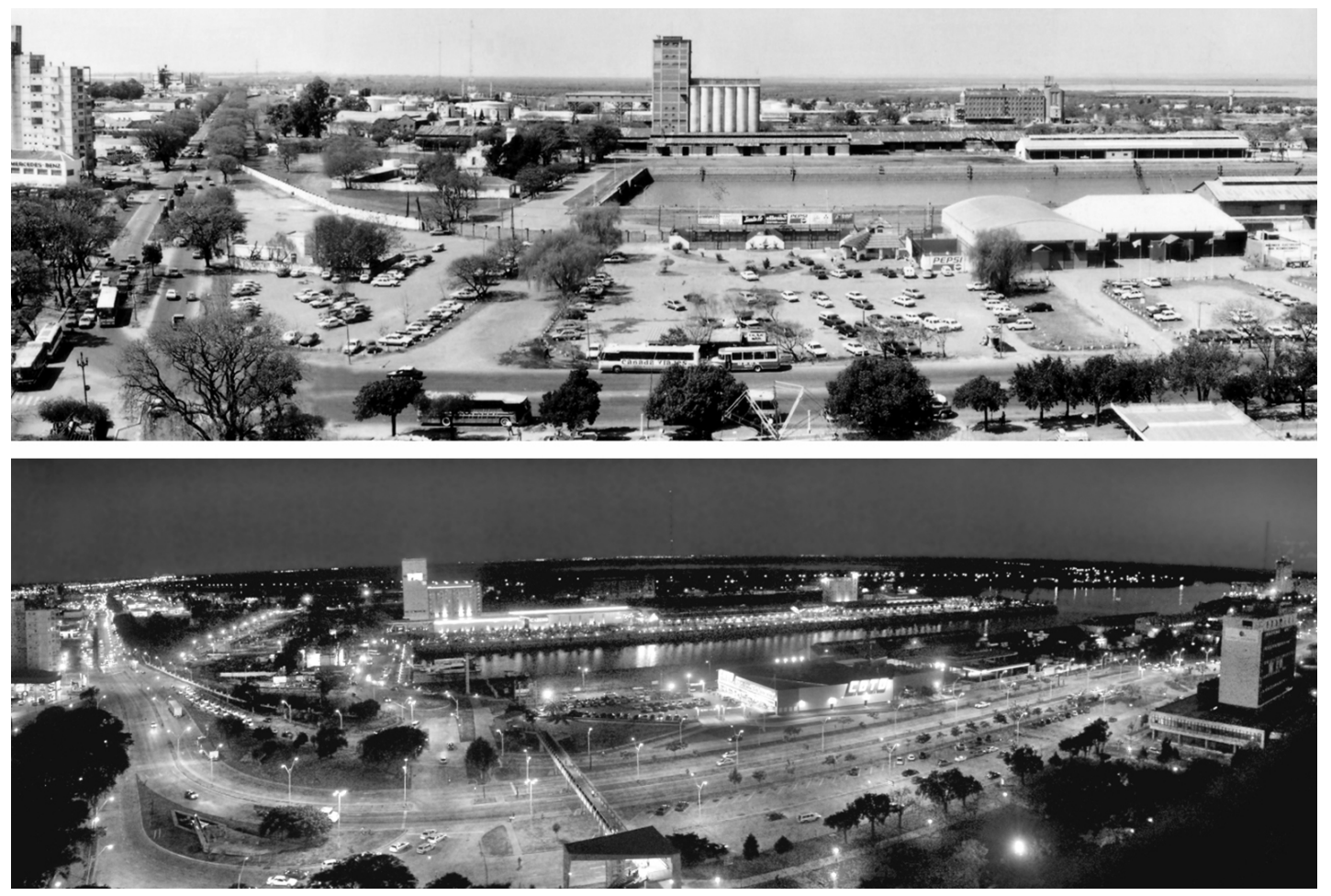

Figura 8. Avenidas Leandro Alem y 27 de Febrero antes y después de la remodelación. Fuente: arriba, fotografía de Javier Fedele, 1993; abajo, fotografía de Mauro Dechiara, 2010 
de la importancia y urgencia de la obra para potenciar la integración territorial de la ciudad y recuperar su histórico lugar geográfico como "nudo de comunicaciones": "Mientras tanto, esta vía de comunicación ya no admite más demoras si es que pretendemos que no nos saquen del mapa y ya nadie pase por Santa Fe" (Diario LA CAPITAL, 8/12/2003). Pese a estas discusiones, y sin demasiados cambios sobre el proyecto original, la obra se inició a principios de 2004 y quedó definitivamente habilitada al tránsito a finales de 2005 (figura 8).

\section{Autovía Ruta Nacional 168 (2007-2011)}

El eslabón pendiente del sistema vial SF-P —es decir, el segundo tramo de la autovía 168no se concretó sino hasta el nuevo siglo. La ejecución de la obra se realizó en dos etapas: la primera de ellas, entre 2007 y 2008, alcanzó una extensión de 3,7 km entre el intercambiador con la RP1 y el acceso al puente sobre el río Colastiné, financiada con fondos provinciales. La segunda etapa se concretó entre 2007 y 2011, y se extendió a lo largo de 9 km entre dicho río y el acceso al túnel subfluvial. Esta vez, la obra fue ejecutada por la DNV con fondos nacionales, y consistió en la construcción de dos nuevos carriles, 1600 metros de puentes aliviadores y en el ensanche del puente ubicado sobre el río Colastiné (figura 9).

A diferencia del primer tramo concretado en la década de 1970, en las discusiones acerca de la definitiva conclusión de la autovía 168 en los años 2000 comenzó a destacarse su inserción en el trazado del CBC Coquimbo-Porto Alegre, como así también la emergencia de nuevos actores interesados en la concreción de las obras:

Tan sólo considerando los últimos tres años, El Litoral dedicó ocho editoriales a los problemas, falencias, urgencias y deseos de santafesinos y entrerrianos respecto de obras necesarias para la ruta nacional $\mathrm{N} .^{\circ} 168$ [...] Sobre el tema se expresaron desde los intendentes de ambas ciudades, sus respectivos concejos municipales, las entidades de la industria y el comercio de mayor peso, y en el caso de nuestra ciudad el Foro para el Desarrollo y la Bolsa de Comercio, entre otros, han hecho infinidad de acciones para llamar la atención de las autoridades (Diario El Litoral, 9/02/2003).

El funcionario destacó que el Gobierno Nacional marcó como “alta prioridad” la finalización de la obra que integra el corredor bioceánico del Mercosur. La importancia de la autovía la certifican los 8000 vehículos que la transitan diariamente. Los que también se mostraron interesados 
Infraestructura e integración regional: la conformación del sistema vial Santa Fe-Paraná entre la conexión de la Mesopotamia argentina y el Corredor Bioceánico Central

en la rápida concreción de la 168 son los funcionarios del gobierno chileno que hace algunos meses recorrieron en persona las obras. Es que el Corredor Bioceánico une Brasil con Chile atravesando la Región Centro (LA Voz, 23/03/2010).

Entre los actores que comenzaron a tener mayor representatividad en las discusiones tendientes a la concreción de las obras para la consolidación del CBC, se encuentra la Región Centro, integrada por las provincias de Entre Ríos, Santa Fe y Córdoba y constituida a partir del Tratado de Integración Regional firmado en el año 1998. En este marco, la participación del sector privado - a través del Foro de Entidades Empresarias y de la Producción de la Región Centro- derivó en la creación de la Red para el Desarrollo del CBC.

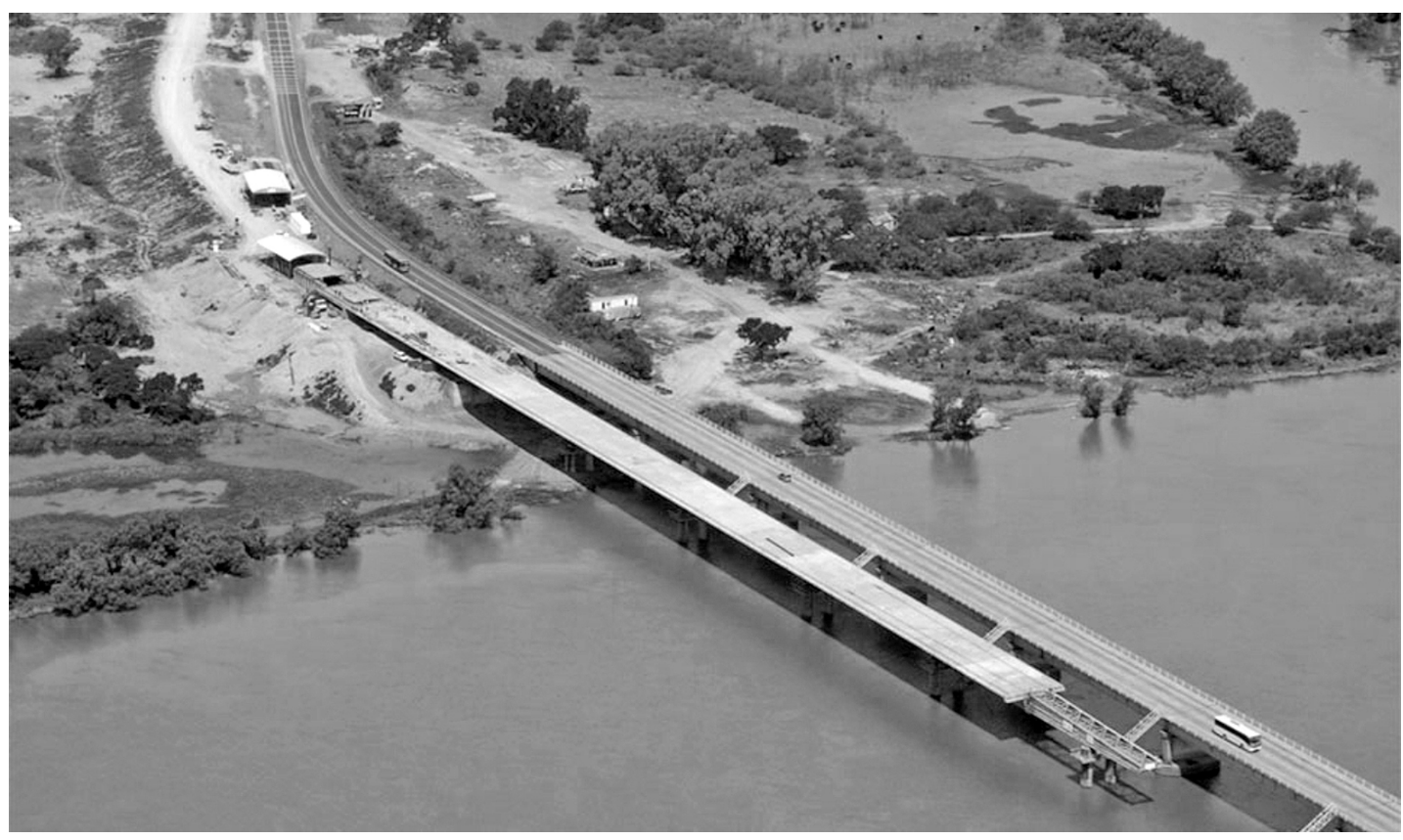

Figura 9. Construcción de la segunda calzada del Puente Colastiné sobre autovía 168. Fuente: SuPERCEMENTO SAIC (2015) 


\section{Autovía Ruta Nacional 19 (2008-2011)}

El proyecto para convertir la RN 19 en autovía se remonta a la década de 1960, como parte del sistema vial SF-P que conectaría ambas ciudades con Córdoba y el centro del país, y como una "complementación lógica e imprescindible de la comunicación subfluvial” (DiARIO El Litoral, 5/10/1970, p.4). No obstante, la obra fue desestimada y postergada varias décadas, precisamente hasta el año 2008, momento en que el gobierno provincial inició las gestiones para construir el tramo correspondiente a su jurisdicción, es decir, entre la ciudad de Santo Tomé y la localidad de San Francisco, con una extensión aproximada de $136 \mathrm{~km}$. Esta vez, las justificaciones del proyecto abogaron por un sistema o conjunto de infraestructura de transporte que integraría las economías del Mercosur y Chile, en el marco de la rehabilitación y mejoramiento del CBC:

Las obras que configuran el Proyecto RN 19 mejorarán las condiciones de tránsito con origen y destino en la región, y del pasante generado desde el Este en las provincias mesopotámicas, Brasil y Uruguay; y desde el Oeste, en las provincias de Córdoba, Noroeste del país, Cuyo y Chile. Se espera que el Proyecto aporte a la competitividad de la economía regional al proveer infraestructura para una logística más eficiente. Del mismo modo se espera que facilite la complementación de las estructuras productivas locales vinculándolas entre sí y facilitando su acceso a los mercados (Gobierno Provincia de Santa Fe, 2006, p. 2).

Nuevamente, a pesar de tratarse de una vía de jurisdicción nacional, el gobierno local asumió la elaboración del proyecto y la ejecución de la obra, a través de un financiamiento otorgado por el Banco Mundial en el marco del préstamo para la Reforma del Estado Provincial. Iniciados los trabajos en el año 2008, la autovía quedó inaugurada a mediados del año 2011, y se aguarda su continuación hasta la capital cordobesa.

\section{Puente Santa Fe-Paraná (pendiente)}

Concluido el sistema vial SF-P, tal como había sido ideado entre las décadas de 1950 y 1970 , puede decirse que su trazado experimentó una suerte de reconfiguración, fundamentalmente a partir de su inserción al CBC. La obra que amerita esta lectura corresponde al proyecto para un nuevo enlace entre las ciudades de Santa Fe y Paraná, materializada en un puente alternativo al túnel subfluvial. El proyecto fue impulsado desde la década de 1990 en el marco de las obras viales vinculadas con el Mercosur, momento en que la participación 
de nuevos actores comenzó a ser relevante entre los impulsos para su concreción:

ésta es la postura de la Unión Industrial de Santa Fe corroborada con la creación del Foro para el Desarrollo de la Ciudad y la Región [...] el escenario mundial se va globalizando exige que las obras de infraestructura estén lo más acorde con el desarrollo de una región. Estos trabajos son los que deciden las posibilidades de las industrias de poder cotizar productos en distintos lugares del mundo (Revista ConeXIón Industrial, diciembre de 1997, p. 15).

Asimismo, bajo el título "Visión del Foro acerca de la integración regional Santa Fe-Paraná", en el siguiente extracto se evidencia el carácter económico que asume la justificación del proyecto y, por lo tanto, la noción de integración regional:

dada la situación geopolítica en que se encuentran Santa Fe y Paraná -sobre uno de los corredores de flujos económicos y comerciales del MERCOSUR- le permiten acceder a reales ventajas competitivas en el marco del acuerdo económico continental y demanda articular alianzas estratégicas para captar uno de los flujos económicos comerciales de mayor importancia: EL CORREDOR BIOCEÁNICO CENTRAL PORTO ALEGRE-PARANÁ-SANTA FE-COQUIMBO [...] En este sentido, creemos que la inversión productiva se va a desarrollar en la medida que se renueven los obstáculos que condicionan a los sectores privados en su decisión (REvisTa ConeXIón IndusTrial, agosto de 2000, p. 22).

A pesar del impulso que recibió la concreción de esta obra en el ámbito local, el proyecto no se realizó sino hasta el año 2014, momento en que se desencadenó un intenso debate vinculado con la ubicación de su trazado. No obstante, tras la resolución del conflicto y elegida la traza definitiva (figura 2), la obra se encuentra aún pendiente.

\section{Recapitulación}

Los puentes, las avenidas de circunvalación, el túnel subfluvial, la autopista y las autovías examinados más arriba constituyen un conjunto de obras viales que conforman el sistema vial SF-P. Un sistema integral cuyas obras se idearon en tanto eslabones de "un todo orgánico de extraordinario valor", concebidas como soportes necesarios para el desarrollo y la modernización del territorio - nacional, regional y local-durante el período denominado desarrollista. Precisamente, el año 1958 - momento en que la DNV recobra su autonomía y la DPV es creada como ente autárquico- marcó un punto de inflexión en la materialización de nuevas infraestructuras carreteras. En efecto, la gestión coordinada entre 
ambas direcciones de vialidad da cuenta de la interacción y continuidad del programa desarrollista entre las presidencias de Frondizi e Illia y las gobernaciones de Sylvestre Begnis y Tessio. Un trabajo mancomunado que impulsó la integración de la Mesopotamia al territorio nacional — a través del Litoral—y, al mismo tiempo, la concreción de un sistema vial que reposicionó a la ciudad de Santa Fe como "nudo de comunicaciones".

No obstante, examinar el proceso de ideación y materialización de cada una de aquellas infraestructuras dejó entrever ciertas particularidades del derrotero político nacional en el ámbito local y provincial, precisamente en torno de las justificaciones discursivas que subyacen a la noción de integración regional. En este sentido, se destaca la reivindicación de las provincias respecto de la histórica centralidad de Buenos Aires en los procesos de toma de decisión. Esta voluntad quedó manifestada, principalmente, en el tratado interprovincial firmado por los gobernadores Carlos Sylvestre Begnis y Raúl Uranga para la construcción del túnel subfluvial, eludiendo la opción de ejecutar un puente en el espacio aéreo de jurisdicción nacional. Una hazaña celebrada como una "rebelión del interior frente al centralismo porteño", como una "admiración hacia quienes la historia tendrá que reconocerles el tremendo coraje de haber desafiado la indiferencia ultrajante de la Nación en su vertical gesto federalista". Las críticas también se hicieron evidentes en el marco de la construcción de la autopista Rosario-Santa Fe, ante "la clásica inercia burocrática que en el orden metropolitano retarda problemas o intereses que corresponden a las provincias”, como así también en torno a la construcción del puente y viaducto Nicasio Oroño, cuyas demoras por parte de la DNV impedirían el uso potencial del sistema vial SF-P.

Ahora bien, concluido el ciclo desarrollista en los años 70, las infraestructuras pendientes se materializaron algunas décadas más tarde, por caso, las avenidas circunvalaciones este y oeste, la autovía RN 19 y los tramos faltantes de la autovía RN 168. A diferencia del período precedente, como se detalló más arriba, los aspectos políticos-territoriales que impulsaron la concreción del sistema vial SF-P — es decir, la descentralización del territorio nacional, la integración de la región Mesopotámica, la modernización del país a través de las infraestructuras-mutaron hacia justificaciones discursivas enfocadas en la integración económica de la región Centro en el marco del trazado del CBC. En efecto, la centralidad asumida por el Estado en los procesos de toma de decisión —entre las décadas de 1960 y 1970— se desplazó hacia el sector privado, con una fuerte representatividad de las Bolsas de Comercio y empresarios de diversos rubros en los discursos que impulsan la concreción de las 
infraestructuras. Justificaciones discursivas en torno a ciertos intereses que, evidenciadas paulatinamente desde la década de 1990, se exponen con mayor claridad en la obra aún pendiente del puente Santa Fe-Paraná.

\section{Referencias}

CAMARDA, M. \& MATEO, J. (2018). Las políticas públicas, el túnel subfluvial entre Paraná y Santa Fe y la integración física de la Megapotamia. Revista Transporte y Territorio, (18), pp. 222-245. doi: https://doi.org/10.34096/rtt.i18.4935

DIRECCIÓN PROVINCIAL DE VIALIDAD (1965). Legajo de Obra: Autopista Santa Fe-Rosario-Arroyo del Medio. Tramo: Santa Fe-Rosario. Ministerio de Obras Públicas. Gobierno de Santa Fe.

DIRECCIÓN PROVINCIAL DE VIALIDAD (1988). Evolución histórica de la vialidad provincial. Ministerio de Obras, Servicios Públicos y Vivienda. Gobierno de Santa Fe.

ENTE INTERPROVINCIAL TÚNEL SUBFLUVIAL (s/f). Túnel Subfluvial "Raúl Uranga-Carlos Sylvestre Begnis". Santa Fe-Paraná. http://www.tunelsubfluvial.gov.ar/

GOBIERNO PROVINCIA DE SANTA FE (2006). Estudio Socio Ambiental, Ruta Nacional $N$. $^{\circ}$ 19, Tramo: $R N N .^{\circ} 11-R N N .^{\circ} 158$. Ministerio de Obras, Servicios Públicos y Vivienda, DPV, Capítulo 1.

HERMIDA, R. (2017). El túnel de Agua Negra y el Corredor Bioceánico Central. Revista de la Bolsa de Comercio de Rosario, (1530), pp. 12-20.

LAREDO, I. (1994). Del deterioro y la asimetría hacia una nueva inserción de América Latina en el sistema internacional. En P. Ciccolella, E. Laurelli, A. Rofman y L. Yanes, Integración Latinoamericana y Territorio. Transformaciones socioeconómicas, políticas y ambientales en el marco de las políticas de ajuste (pp. 115-140). Buenos Aires, Argentina, CEUR/UBA.

LUXARDO, J. (1961). Accesos a las Grandes Ciudades. Revista del Centro de Ingenieros Provincia de Buenos Aires, IX(35), pp. 5-23.

MACOR, D. \& PIAZZESI, S. (2011). Santa Fe política, 1955-2010. En D. Macor (Dir.), Signos santafesinos en el Bicentenario. Santa Fe, Espacio Santafesino Ediciones.

MORALES LETZKUS, C. (Dir.) (2014). Potencialidades económicas y de negocios del Corredor Bioceánico Central (CBC) Coquimbo-Porto Alegre. Gobierno Regional de Coquimbo, Chile: Proyecto FIC-R (Fondo de Innovación para la Competitividad). 
MÜLLER, L.; PARERA, C. \& SHMIDT, C. (Eds.) (2018). Arquitectura, Tecnología y Proyecto: obras públicas e infraestructura urbana y territorial en Argentina (19551971). Universidad Nacional del Litoral.

SANAHUJA, J. A. (2008). Del "regionalismo abierto" al "regionalismo post-liberal". Crisis y cambio en la integración regional en América Latina. En A. Laneydi Martínez, L. Peña y M. Vázquez, Anuario de la Integración Regional de América Latina y el Gran Caribe, 7 (pp.11-54). Coordinadora Regional de Investigaciones Económicas y Sociales (CRIES).

SUPERCEMENTO SAIC (2015). Obras viales. Puentes. Ruta Nacional $N^{\circ} 168$. Buenos Aires, Argentina. http://www.superdyop.com.ar/obras-publicas/viales/puentes. html

\section{Fuentes primarias (revistas, boletines y artículos periodísticos)}

(18/03/1959). Tendrá 500 metros de extensión y costará casi 60 millones de pesos el puente sobre el Colastiné. Diario El Litoral, p. 4.

(29/12/1959). La construcción del puente sobre el río Colastiné progresa con ritmo sostenido. Diario El Litoral, p. 4.

(25/05/1960). Un nuevo puente sobre la Setúbal proyecta Vialidad Nacional. Diario El Litoral, p. 5.

(4/10/1960). Fue decidida la construcción de un nuevo y moderno puente sobre la Laguna Setúbal. Diario El Litoral, p. 5.

(Diciembre de 1964). El Túnel Subfluvial es una realidad en marcha. Revista La Nota Santafesina, pp. 6-9.

(5/10/1966). Se construirá un camino contiguo a la actual ruta 168, la que se transformaría en autopista. Diario El Litoral, p. 4.

(21/01/1967). Luego de siete años de labor y tras solucionar inconvenientes imprevistos, terminan un puente. Diario El Litoral, p. 3.

(Diciembre de 1967). Única en Sudamérica: Una obra de la que se venía hablando ya en 1911. Revista Tiempo, pp. 32-33.

(12/03/1968). A principios de abril comenzarán las obras de repavimentación total de la ruta nacional 168. Diario El Litoral, p. 3.

(Septiembre de 1968). Santa Fe y Paraná no deben quedarse de simples mojones. Revista Tiempo, p. 7. 
(5/07/1969). La habilitación del primer tramo de la avenida de circunvalación y urgencia de su prolongación. Diario El Litoral, p. 4.

(13/12/1969). Fue inaugurado el túnel Hernandarias. Diario El Litoral, p. 1.

(14/12/1969). El túnel fue librado al servicio público. Diario El Litoral, p. 1.

(5/10/1970). Autopista en discusión. Diario El Litoral, p. 4.

(14/01/1971). Libran al servicio el puente Setúbal. Diario El Litoral, p. 1.

(25/09/1971). Trascendente significado de la habilitación de los sistemas de acceso al puente "Setúbal". Diario El Litoral, p. 4.

(18/11/1971). La autopista Santa Fe-Rosario ha sido habilitada al tránsito. Diario El Litoral, p. 4.

(25/06/1972). La autopista Santa Fe-Rosario. Diario El Litoral, p. 4.

(4/10/1972). Habilitóse la autopista de Santa Fe a Rosario. Diario El Litoral, pp. 1-2.

(21/01/1973). No habría continuidad entre los puentes de la ruta $\mathrm{N}^{\circ} 168$ y sus correspondientes terraplenes. Diario El Litoral, p. 4.

(23/01/1979). La habilitación de una calzada de la nueva ruta S. Fe-La Guardia. Diario El Litoral, p. 4.

(20/09/1979). Convenio de traspaso de la autopista a la provincia. Diario El Litoral, p. 4.

(Diciembre de 1997). Apoyamos el Puente Santa Fe-Paraná. Revista Conexión Industrial, p. 15.

(Agosto de 2000). Gestiones de entidades intermedias para la pronta ejecución del Puente Santa Fe-Paraná. Revista Conexión Industrial, pp. 22-23

(9/02/2003). La ruta 168 y un rosario de promesas sin cumplir. https://www.ellitoral.com/ index.php/diarios/2003/02/09/metropolitanas/AREA-01.html

(3/11/2003). Se oponen a la multitrocha para Alem y 27 de Febrero. http://www.ellitoral. com/index.php/diarios/2003/11/03/metropolitanas/AREA-01.html

(8/12/2003). Polémica en torno a una importante obra vial en la ciudad de Santa Fe. Diario La Capital. http://archivo.lacapital.com.ar/2003/12/08/region/noticia_59479.shtml

(23/03/2010). A fin de año la 168 será autovía. La Voz. https://www.lavoz901.com/noticias/afin-de-ao-la-168-ser-autova.htm 
Artículos 